\title{
Editorial
}

\section{Risk Management (2016)}

Risk Management (2016) 18, 1-3. doi:10.1057/rm.2016.2

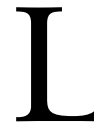

et me first start my first editorial as the new editor-in-chief of the journal by thanking the previous Editors, Denis Fischbacher-Smith and Moira Fischbacher-Smith, for their work and efforts in running and developing the journal. The articles in this issue of Risk Management are related to the earlier aims and scope of the journal and were handled by the previous Editors.

The Risk Management journal goes back to 1999 when the first issue was published. There have been many changes since then: technological advances have brought about 'disruption' in many industries, and the onset of new ones; the world's geopolitical landscape has been reshaped; and the most recent global financial crisis, of unprecedented scale and scope, just to name a few of the most profound ones.

The way industry and academia see and understand risk management theory and practice has evolved and changed over that time as well. In particular, in the aftermath of the most recent global financial crisis issues related to risk management drew much more attention and became 'hot topics' of legislative, regulatory, professional and academic debate. Risk management courses are now a standard part of most business studies curricula and in particular one of the key components in studies related to finance. In many corporations there are top management posts that require specializations in risk (Chief Risk Officer).

What has not narrowed much though, is the gap between academia and industry. We still seem to be standing on opposite sides of the crevasse, albeit with similar if not the same goals. We either do not talk/listen to each other, or messages 'get lost in translation'. While there are many journal outlets that cater to academics, there are very few outlets that are aimed at both academics and practitioners. With the re-launched Risk Management journal we aim at narrowing that gap — reaching across — by getting academics, practitioners and regulators to talk and listen. We seek to address topics that are relevant to practitioners with academic rigor and disseminate them in applicable fashion.

A more profound change of the re-launched Risk Management journal is in its focus. The journal previously addressed risk management issues from a broader, societal context, applying predominantly qualitative analysis and 
proposing conceptual solutions. The re-launched journal will focus on financial risks, related aspects of risks that feed into financial risks, and risks in financial institutions. We are looking for application of academically rigorous quantitative solutions to complex practical issues. In other words, the journal seeks to facilitate an exchange of knowledge between academics and practitioners in the area of financial risk management.

From the perspective of the taxonomy of financial risks, we will look directly at the issues related to credit and market risks in different markets (FX, commodities, credit market), as well as indirectly at relevant operational risks that feed into financial risks (cyber risk for example). As the relevance, treatment, regulation and impact of those risks can differ substantially at the institutional level, we seek to separately address those in terms of banks and insurance companies, asset management companies and non-financial companies.

The challenges we are all facing these days are numerous. The global financial and economic crisis has brought many banking systems down to their knees. Although the governments stepped in and bailed-out many ailing banks and financial institutions, the changes in regulation provide serious challenges to the future of banking. In addition to this, a particular evolution and use of technology (commonly referred these days as fintech) in finance is disrupting traditional business models in financial markets, as well as bringing about new and unchartered risk territories. The institutionalization of advances in financial technology (in trading in particular) over the past decades have spurred changes in the microstructure of financial markets. Many recent 'scandals' in finance have uncovered a new set of risks that need to be addressed. Asset management companies are in need of reinventing their business models in the expected prolonged period of low interest rates and low economic growth, where the riskreturn tradeoffs of many assets are unfavorable. With traditional banks incapacitated and low yields, insurance companies in many local markets have ventured into realms of shadow banking, exposing themselves to potential risks they are not wellprepared to manage. Many non-financial companies are (falsely) complacent about many financial risks, given the low interest rates and slump in commodity prices.

In addition to the challenges posed by the ever-changing financial and economic landscape, there are new opportunities originating in advances in data and human sciences. Technological advances provide opportunities when it comes to the quality, quantity and frequency of data (big data), as well as the ways in which we are able to analyze such data, in particular unstructured data (data science). These advances will most likely increase the levels of automation when it comes to many (financial) decisions, as well as the interconnectedness between individuals, institutions and markets. Such developments will take us into new territories when it comes to model and correlation risks.

For better or for worse, we live in interesting times. What we call them, whether we are in the normal or the new abnormal, is not really relevant. 
What is important is to understand the challenges and/or opportunities we are faced with; to investigate and discuss the potential solutions; and to analyze implications within the institutional and market-wide contexts. We need to start listening to each other.

Igor Lončarski

Editor-in-Chief. 